\title{
Research on Cultivating Undergraduates in the Computer Science Based on Students
}

\author{
Qiongqin Jiang, Tian Jin, Wenguang Song \\ School of Computer Science, Yangtze University, Jingzhou, 434023, Hubei, China \\ E-mail: jqq@yangtzeu.edu.cn, wenguang_song@yangtzeu.edu.cn \\ Haiyu Chen* \\ Department of Computer,Zhaoqing Medical College,Zhaoqing, 526020, Guangdong ,China \\ Email: jsj-3782036@126.com*
}

Received: 14 August 2020; Accepted: 25 November 2020; Published: 08 December 2020

\begin{abstract}
According to the existing problems in college students' learning, change the teaching method to cultivate students with innovative consciousness and innovative connotation. The article mainly elaborates on the current shortcomings in the teaching process of many ordinary colleges and universities, and proposes that teaching is mainly secondary school; teaching is supplemented, and student-oriented. The main responsibility of teachers is to guide patiently, actively communicate with students, and teach students in accordance with their aptitude. First teachers should understand the student's learning dynamics from the student's perspective, and then prescribe the right medicine to correct its drawbacks, encourage its advantages, and cultivate students' learning enthusiasm. Teachers stimulate students to learn actively, recognize their learning effects, and encourage students to experiment boldly and be creative. The students are more motivated to learn, build self-confidence in learning, and have a sense of innovation. According to the curriculum and being student-oriented, teachers prepare lessons, write lesson plans, design teaching links and do a good job in class counseling, which cultivate students' sense of innovation and enable students to have innovative connotations.
\end{abstract}

Index Terms: knowledge, innovation, Talent training, Student-oriented

\section{Introduction}

Being student-oriented is mainly to treat students as confidantes, appreciate the existing environment of students, and communicate with them fully, so as to achieve the purpose of recognizing the current situation of students. Teachers should combine the present teaching environment, make full use of teaching methods, teach students in accordance with their aptitude, and attempt to cultivate innovative talents, play a role in promoting mutual learning.

The National Medium and Long-term Education Reform and Development Plan (2010-2020) in china talks about exploring ways to discover and train innovative talents. In this regard, I make the following conclusions, combining with the teaching methods which I tried in my teaching. First, the teachers must use the students' perspective and attitude to think about the problem during the teaching process, and cannot blindly fill the students with knowledge. Second, the teachers should let students learn autonomously, at the same time, encourage them to learn actively. In addition, teachers should pay attention to the way students are treated before criticizing their shortcomings, on one hand, teachers should encourage their positive aspects, and then give appropriate corrections, appropriate guidance, and encourage their learning enthusiasm. Finally, as long as they do not go against the principle, students are encouraged to take the initiative to try, so that students can discover and solve problems by themselves. Doing so can activate students' learning thinking, affirm their learning achievements, stimulate their active learning, boldly discover and solve problems, so that when they encounter problems, they can consider problems from multiple angles, understand things, and discover things that ordinary people can't see .Therefore, it can achieve the purpose of cultivating students to have innovative consciousness and innovative connotation.

\section{Situation Analysis}

It has been more than ten years since the teaching reform was proposed, but there are still many problems in our university teaching process. More than $70 \%$ of the teachers' teaching concepts cannot keep up with the times. They always follow the textbooks and think that the content in the textbooks should be explained. It often appears that teachers will be full of lectures, and students will not even have a chance to express their opinions. They believe that in the teaching 
process, it is mainly teachers who teach and students are just passive recipients. Teachers ignore students' initiative in learning and forget that students are the dominant position in the teaching process. This kind of classroom atmosphere is dull, so students' perceptions and experiences in the learning process are not fed back in time, and the teacher's teaching effect cannot be tested when the students' feedback is not available. Of course, the teacher's teaching quality cannot be tested, and the teacher's level of teaching and educating is also difficult to quickly improve. At the same time, the longterm full teaching and the inability to conduct teacher-student interaction well dampen students' learning enthusiasm and initiative. Due to the loose management of the school system in university education, many students will have the idea that 60 scores is enough. They think that they can graduate successfully from university, so they have missed the best learning time in their life. It is difficult to think proactively in their work after graduation, let alone innovation.

In addition, some university teachers do not have solid basic skills, have insufficient grasp of the overall subject teaching, imperfect systematic knowledge, and weak self-awareness. They are content with the teaching of forty-five minutes class, and do not take the initiative to discover, delve into, and explore new knowledge. They believe that the teacher's responsibility is only to give lectures, if they finish the lectures, their tasks are completed. Whether students have mastered it has nothing to do with them. As for the teaching results, they did not expect them at all. They have not done any survey on teaching quality feedback, and they are not responsible for the teaching results, which also directly affects the quality of teaching.

Most of the students in university classrooms were born after 2000. Because they were only children at home, their parents, grandpa, and grandma devoted the love and care to them, and most of them were spoiled. Therefore, many students are self-centered, including learning. What they think is not how to learn well, but how to enjoy themselves. Therefore, many students only want to "enjoy" life, believing that they only need to pass the exam and live as they please. From the bottom of their heart, they didn't really realize the importance of learning to gain future success. Therefore, in some classes, teachers were teaching while students were playing. The relationship between teachers and students is almost parallel. The atmosphere in the class is dull. The more students don't want to learn, the more teachers are reluctant to teach.

Therefore, for our teachers, we must not only deeply understand the current learning status of college students, analyze its deep-seated reasons, but also continuously improve their own teaching process in a targeted manner, induce students to actively learn, and cultivate students' learning initiative. Teaching in thinking and exploration, so that teaching can be explained vividly and lively, and teachers and students can get along in harmony.

\section{Student-oriented talent training}

In the reform of the talent training system, the innovative talent training model is mentioned. The innovative talents meet the needs of national and social development. They must follow the law of education and talent growth, deepen the reform of education and teaching, innovate education and teaching methods, explore multiple training methods, and form various Such talents are emerging in large numbers and top-notch innovative talents continue to emerge. This is an important responsibility we shoulder as teachers.

\subsection{Student-oriented main requirements}

To be student-oriented, we must first focus on teaching students in accordance with their aptitude. Teachers should pay attention to the differences of students' personalities, consider the differences of each student's own living environment, and develop each student's superior potential. For example some excellent students, we don't need to restrain them a lot, we should give them appropriate guidance, indicate their learning direction, inform them of their learning goals, and help them analyze and resolve the important and difficult points in learning. The main thing is to tell them how to learn. Middle level student is the majority of students we face. They have a certain degree of self-discipline [1]. Wang Wei, Ishi Yefei, Jiang Li. Long-term training mechanism for innovation and entrepreneurship ability of design college students based on school-enterprise cooperation. Science and Technology Wind, 2018(33):233.We must first find out the learning status and personal characteristics of these students, and then treat them in different categories according to their respective characteristics, except for them to know clearly. In addition to the purpose of learning, we must also tell them how to learn, and teach them hand-in-hand when appropriate. Students who don't like learning, this is for students who want us to invest more effort. First of all, we must cultivate their interest in learning, so that they can gain daily and make progress every time they learn. In this way, with the joy of success, we can tell them that they are actually learn better.

Being student-oriented, teachers should let students combine learning and thinking and let students be the main body of learning. Teachers use advocacy, inquiry, discussion, and participatory teaching in the class to help students how to learn. Teachers should encourage students to think positively, study diligently, explore in depth and stimulate students' curiosity, cultivate students' hobbies, and create a good environment for independent thinking, free exploration and innovation [2]. To meet the requirements of economic and social development and scientific and technological progress, we should promote curriculum reform, strengthen the construction of teaching materials, and establish and improve the quality control system of teaching materials. We also we need to do in-depth research, determine the core content that students must master at different stages of education, and form a teaching content update mechanism. All teachers are supposed to give full play to the role of modern information technology and promote the sharing of high-quality teaching 
resources.

Being student-oriented, finally we should achieve unity of knowledge and action unity. We should persist in the combination of education and teaching with production labor and social practice. And develop practical courses and activity courses to enhance the effectiveness of students' scientific experiments, production practice, and skill training [3]. In addition we are supposed to make full use of social education resources to carry out various extracurricular and extracurricular activities, strengthen the construction of venues for activities outside primary and secondary schools and strengthen the organization and guidance of student associations and encourage students to actively participate in volunteer services and public welfare undertakings, which can cultivate students' sense of social responsibility.

\subsection{Student-oriented implementation in classroom teaching}

As teachers, to be student-oriented, we also need to do more preparations after class. First, we must delve into the ten textbook standards, secondly prepare the lessons carefully, then write a good lesson plan, and finally pay attention to the flexible use of teaching links [3]. But they need deals with a problem (studied by the authors for several years) of the cognitive barriers (difficulties) related to the third component of a peda-gogical triad "how to learn, what to learn, how to study".[4]

Based on personal experience, the following ten items are summarized as to how to study textbooks. First, the position of the course in the entire subject system must be clear, and basic concepts, formulas, and laws must be kept in mind in teaching, and be able to use them freely. Second, article is to understand the system of the whole book, the status and function of each chapter, and the purpose of teaching must be clarified before teaching the entire book, so the teaching must be focused on priorities and flexibly explained. Third, we should inform students of each chapter The purpose of learning [5]. The key and difficult points of each chapter must be clearly told to students. Fourth, teachers must clearly know the teaching objectives of each chapter and the corresponding points in the syllabus and must clearly told the students, and also we should be able to classify teaching objectives in educational psychology. Fifth, teachers should learn to empathize, consider students' difficult points and predict possible problems. Sixth, we need to provide some teaching reference materials and be good at using materials to make students understand the knowledge. Seventh, we should let students learn knowledge association, make good use of students' old knowledge to make students understand new knowledge. Eighth, we should provide timely extracurricular tutoring to students, and make good use of students' extracurricular knowledge to understand students' in-class knowledge. Ninth, we should be familiar with the advantages and disadvantages of the textbooks, understand the intention of the textbook compilation, and properly inform students of the reference textbooks, so that students can find answers that they recognize in multiple related textbooks [6]. Tenth, we should make good use of teaching aids during teaching And language intuition to teach students. After we make in-depth study of the textbook, lesson preparation is an important part of our service to students. [9] have worked on project-based frameworks for organizational training and learning and have attempted to validate them in the software developmental organizations and in an institution teaching software engineering.

The main tasks are to be completed for lesson preparation. First, study the curriculum standards, study the teaching materials and teaching reference materials according to the curriculum. Second, understand the situation of the students, and teach students in accordance with their aptitude[7]. Third, we should determine the teaching goals and choose the teaching methods according to the students. Determine the teaching procedure. Fourth, we need to compile semester schedules, unit teaching schedules and lesson plans according to the ability of students to master their knowledge and the mastery of the advanced courses [5]. For specific lesson preparation, we need to pay attention to these eight points. First, the purpose of the course teaching should be clear, the purpose of each book, the purpose of each chapter, and the purpose of each lesson should be clear to the students. Second, we need to be familiar with the writing principles of the course, use the knowledge in the book to guide students appropriately, and not copy the book, but not divorce it from the book. Third, we should design a good writing system, use the knowledge in the book to guide students and explore knowledge. Fourth, the teaching method should be adapted to the teaching of this course. And we need to design teaching methods for different classes and courses to stimulate students to learn actively and actively. Fifth, We should be clear about the class hours of the entire course. In order to achieve the teaching goal, we need to know what content should be taught in each class, and what knowledge should be mastered in each class, and should be clear. Sixth, when we prepare lessons, we must pay attention to the teaching points of each topic to be clear, and we must clearly tell students when teaching. Seventh, we need to design homework, practice assignments, extracurricular readings, and reference materials for each topic[9]. Eighth, we need to repeatedly study and complete the understanding of the outline knowledge points. All of these are for the purpose of teaching students better, and are also specific student-oriented preparations.

When compiling teaching plans, teachers must have clear teaching goals, and the analysis of teaching content must have a reasonable hierarchical structure. Students' level must be investigated and understood before class, so that the content of the class can adapt to the students' ability to understand and absorb, the types of courses during the class, Methods, teaching hours, teaching steps, etc. should be specified in the teaching plan, and the teaching should be organized according to the lesson preparation and teaching plan during the teaching [8]. In order to make progress in teaching, it is necessary to write a teaching postscript after each class. In order to degrade the course better in the next lecture. 


\subsection{Solutions}

Step 1. The construction of teaching staff for student training

The teaching staff is the core competitiveness of the college development, and young teachers are the reserve force for the sustainable development of the college. All young teachers are required to study for doctoral degree, expand their knowledge structure and increase the proportion of doctors in the college. The construction of teaching staff should focus on optimizing the structure, comprehensively improving the overall quality of teachers, fully improving the teaching and scientific research level of teachers, focusing on the cultivation of backbone teachers and subject leaders, and taking the introduction of excellent talents and strengthening training as important measures, so as to build a teachers team with high academic level, excellent business, rigorous scholarship, full of vitality and sustainable development.

The construction of teaching staff is carried out from these four aspects. First, we should combine the introduction and training measures to implement the project of "doctoral" of young teachers. Second, optimize the structure of the teaching staff and improve the overall quality of teachers. Third, efforts should be made to build a teaching and research platform to improve the teaching and scientific research level of teachers[11]. Fourth, introduce, select and cultivate academic leaders, academic leaders and academic backbones.

Carry out teaching reform and personnel training

(1) Expand school enterprise cooperation, explore and promote the talent training mode suitable for social and economic development. In accordance with the talent training policy of "strengthening the foundation, broadening the specialty, paying attention to practice and cultivating ability", we should deepen the teaching reform, strengthen the teaching management and improve the teaching quality with the guidance of changing the educational thought and renewing the educational concept. Taking the revision of talent training plan as the breakthrough point, we should make clear and grasp the direction of professional development, determine the training objectives, optimize the talent training mode, construct excellent curriculum system, and improve the talent training plan; reform the teaching content, methods and means with the teaching reform as the driving force; improve the overall quality of the teaching staff and the quality of personnel training with the construction of the teaching staff as the guarantee; and improve the quality of personnel training through management System reform as a means to establish an efficient teaching management system.

It is necessary to carry out in-depth research on teaching contents, teaching methods and teaching means, update outdated teaching contents, explore and implement new teaching methods and means, and carry out teaching method reform centering on Strengthening Students' innovative spirit and practical ability[12]. We should pay attention to the cultivation of students' self-study ability, problem analysis ability, problem-solving ability, practical ability and innovation ability, as well as the all-round development of students' personality and talents. Actively adopt heuristic, discussion, discussion, cooperation teaching methods. Improve the quality of multimedia courseware to ensure the actual effect of classroom teaching. To explore the examination method of laying equal emphasis on theory and practice.

It is necessary to strengthen the cooperation between colleges and enterprises, form a talent training system with our own characteristics, and make the quality of personnel training step into the advanced ranks of similar domestic colleges and universities, with strong social adaptability and competitiveness.

(2) Establish a forward-looking professional curriculum system. On the basis of making clear the training objectives and specifications of professional talents, we should optimize the talent training scheme and establish a curriculum system suitable for the training objectives[11]. In the process of curriculum system reform, the application of emerging Internet of things technology, cloud computing, big data and other systems should be integrated into the teaching content; in the teaching form, the emphasis on theory and light of practice should be transformed into paying attention to practice, the cultivation of practical ability and innovation ability should be strengthened, and the theory and practice education in class should be combined with extracurricular practice, so as to ensure that students have a solid specialty At the same time, improve students' practical ability and adapt to the environment and platform of emerging technology.

(3) We should establish an open and innovative practical teaching platform to cultivate talents with individuality and diversity. We should strengthen the reform and construction of practical teaching, and actively explore and implement a practical teaching system integrating teaching and learning, theory and practice, in and out of school, in class and after class, and practical ability training and discipline competition. We should regard practicality, openness and innovation as the goal of experimental teaching platform construction, meet the needs of different levels of practice, achieve diversified training objectives, and meet the needs of different students' personality development. It is necessary to strengthen the cooperation within and outside the school, establish a batch of "production, teaching, research and application" training and practice bases, and cultivate applied talents who meet the actual needs of the society.

(4) Complete the "whole person" training and realize high salary employment and innovative employment.

While improving students' comprehensive practical ability, we should cultivate students' innovative consciousness, entrepreneurial consciousness and innovative ability, strengthen the cultivation of students' team spirit, cooperation ability, expression level, literature retrieval, foreign language level and other aspects of comprehensive quality training, effectively cultivate "two innovation" talents, enhance students' Employment Competitiveness and innovation and entrepreneurship ability, and promote students' goal of "whole person" development[14]. It is also necessary to guide students to actively participate in the "College Students' innovation and entrepreneurship training program", encourage students to participate 
in provincial and national "Challenge Cup" competitions and various disciplines competitions, and strive to win prizes.

Step 2. Carry out school enterprise cooperation and innovate teaching reform mode

(1) Continue to cooperate with Beijing Jurassic Software Co., Ltd. to set up "petroleum application software experimental class", and implement the reform of talent training mode of school enterprise cooperation. And conscientiously summarize and promote the management experience and teaching mode of experimental class in ordinary classes.

(2) According to the needs of new technology and national economic strategy, "computer experimental class" is set up. Based on Internet of things, big data and cloud computing, we need to train talents for the national strategic needs in the era of Internet plus.

(3) Actively strive for school support, organize human resources well, strive for computer major to obtain provincial teaching reform quality engineering project during the 13th Five Year Plan period, and achieve "zero" breakthrough in quality engineering.

Step 3. Strengthen the cultivation of practical and innovative ability, and highlight the research-oriented and innovative learning

Continue to set up "College Students' interest study group". According to the embedded development, web application development, mobile application development and other directions, the team is set up to strengthen the cultivation of students' practical ability and innovation ability. Teachers are encouraged to guide students to carry out extracurricular scientific and technological activities, practical innovation and discipline competitions, and awarding students, instructors and class teachers. For example, teachers who guide students to obtain provincial and above awards, publish papers and obtain patents will be given corresponding awards according to the award level. Under the same conditions, students will be given priority to obtain the qualification of postgraduate promotion and exemption.

Step 4. Strengthen curriculum construction and improve teaching and research level

(1) We should pay attention to the construction of excellent courses at school level and cultivate the provincial curriculum construction projects. The follow-up construction of "computer network" and "software engineering" courses is in the charge of the specialty, and other school level curriculum construction projects should be constructed according to the provincial standards. During the construction process, the college provides funds and equipment support.

(2) Strengthen teaching research. During the 13th Five Year Plan period, teachers with associate professor title or above are required to apply for 1-2 teaching and research projects. Teachers with the title of lecturer or above must publish a teaching and research paper every two years.

(3) We should implement the curriculum responsibility system, actively carry out the construction of teaching materials, and cultivate and plan teaching materials. At the college level, a large number of professional basic courses and professional core courses are planned, organized and determined. The curriculum responsibility system is implemented in a planned way. The teaching material construction is taken as an important assessment basis for the teaching team. The practical and innovative teaching materials that have been used for two years or more are cultivated according to the planned teaching materials and subsidized according to the college policies.

Step 5. Strengthen the construction of innovation laboratory and expand the practice and training base

(1) We should raise funds from various channels and strive for various laboratory construction projects. Summarize the experience of laboratory construction, strive for the central financial and local joint construction of university laboratory projects, and strive for enterprises to invest in laboratory construction projects.

(2) We should strengthen the demonstration and management of the use of funds and highlight the key points of construction[13]. It is necessary to scientifically plan the laboratory producing area, experimental projects and experimental conditions. On the premise of improving the laboratory environment, we should focus on the experimental projects which are innovative and conform to the discipline development plan of the college and the national development strategy.

(3) Efforts should be made to improve the experimental conditions and implement the construction of open laboratory. It is necessary to actively reflect to all departments of the school and strive to use two floors of the experimental building (Bishop) as the computer laboratory room in the planning and adjustment of the school housing, so as to relieve the pressure of the laboratory room and improve the experimental conditions and environment. And strengthen cooperation with the relevant departments of the school, solve the problems of access control and monitoring, and realize the automation and digitization of laboratory management.

(4) Strengthen the construction of laboratory team. During the 13th Five Year Plan period, the laboratory team should be scientific in construction, standardized in management, master's degree and professional in experiment[14]. According to the principle of combining full-time and part-time jobs, the service awareness and service level of laboratory team should be improved, and the laboratory management personnel should be encouraged to study further to improve their professional level.

(5) The contents of experimental teaching should be revised with the times, and the experimental items of design, comprehensiveness, research and innovation should be highlighted. JWith the continuous emergence of new computer technologies and platforms, it is necessary to adjust the experimental contents accordingly, and highlight the close integration of experimental projects with our school's dominant disciplines (such as petroleum, agronomy, Jingchu culture, etc.) or national strategic needs (big data, cloud computing, Internet of things, etc.). 
(6) Make full use of off campus resources, expand the construction of practice and training base, encourage teachers to write high-quality experimental handouts and experimental cases, and give subsidies according to the policy of the college.

Step 6. Formulate incentive mechanism to encourage teaching innovation

According to the classification, we will formulate the reward and subsidy policies of the college, such as teaching and research papers, awards of teaching achievements, awards of discipline competitions, building materials construction, excellent courses, practice case design, etc., and give priority to the promotion of professional titles and project evaluation.[15]

Expected results: the professional structure is reasonable, the characteristics of talent training program are obvious, the curriculum and practice system can reflect the new technology and method in the information age, and are forwardlooking; the practice bases inside and outside the school are basically complete, the reform of talent training mode of "school enterprise cooperation" and "college enterprise cooperation" is more in-depth, and students' practical ability, employment competitiveness, innovation consciousness and ability are improved To further improve; to improve the style of teaching and learning, teachers' teaching ability and teaching level have been improved; the laboratory team has achieved specialization, teaching research has become a common practice, teaching team is basically stable and distinctive; in the curriculum construction, teaching material construction, practice engineering center construction, teaching reform and other aspects, the provincial quality engineering "zero" breakthrough, research-oriented, research-oriented, and so on has been achieved The innovative teaching effect is obvious, and plays a leading role in demonstration.

\section{Teaching case analysis}

According to the teaching and training link designed by the author, taking students as the original, engaged in the teaching work of advanced application of office automation, a public elective course in Yangtze University. In the teaching process, the first class clearly tells the teaching objectives that should be achieved after learning the course, as well as the detection means. When teaching each software technology, I clearly tell the purpose of learning and the skill requirements to be achieved after learning. For example, when learning word 2010, first I tell students that they should be able to edit and typeset books, newspapers and advertisements with word 2010 after learning as figure 1.

\section{Word processing}

\section{Text editing function}

2. Form processing function

3. Layout function

4. File management function

5. Create WEB page function

6. Spelling and grammar check function

7. Powerful printing function and compatibility, etc.
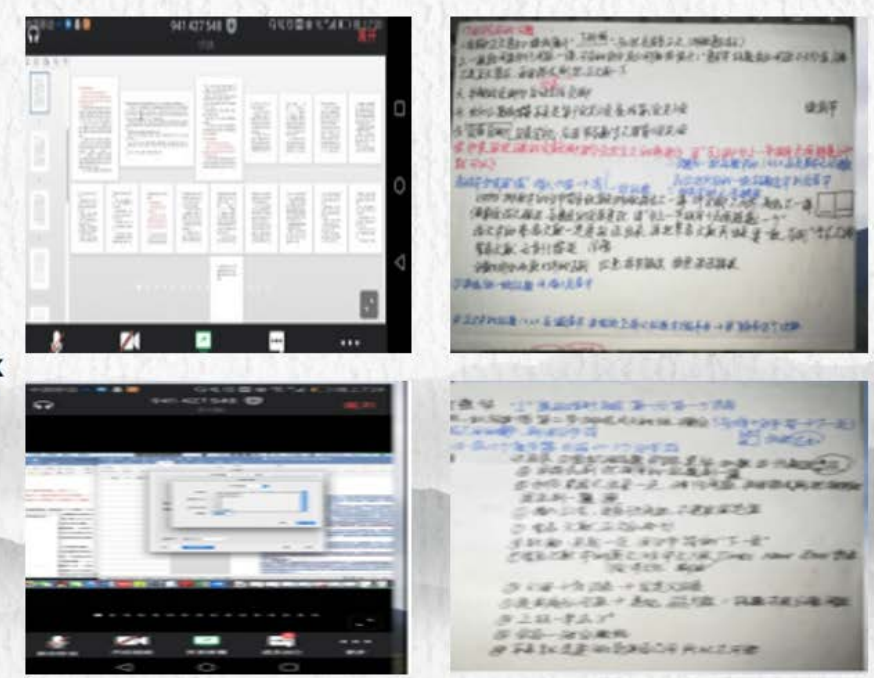

Figure 1. Learning effect of word 2010

Therefore, in the process of learning, students will be asked some relevant questions, teachers can also have targeted counseling students, and tell students that different methods can get different results. In this way, students in the process of practice, learning and thinking, different students with different methods, all roads lead to Rome, promote students' divergent thinking, consciously seek new methods. It has trained the students' innovative consciousness. By the innovation of teaching content, experiment method, teaching method, test method, some experience are expatiated on improving quality as table 1 show. 
Table 1. The effect of contrast teaching after improvement

\begin{tabular}{|c|l|l|l|l|}
\hline Ordinals & $\begin{array}{l}\text { Learning } \\
\text { Content }\end{array}$ & Learning Skills & $\begin{array}{l}\text { Improvement Percentage of } \\
\text { Teaching Effect }\end{array}$ & $\begin{array}{l}\text { Skill Improvement } \\
\text { Percentage }\end{array}$ \\
\hline 1 & Word 2010 & $\begin{array}{l}\text { Case analysis of long word } \\
\text { document typesetting }\end{array}$ & $85 \%$ & $75 \%$ \\
\hline 2 & Excel 2010 & $\begin{array}{l}\text { Excel statistical template } \\
\text { making }\end{array}$ & $80 \%$ & $73 \%$ \\
\hline 3 & $\begin{array}{l}\text { Powerpoint } \\
2010\end{array}$ & $\begin{array}{l}\text { Automatic PowerPoint slide } \\
\text { production }\end{array}$ & $90 \%$ & $89 \%$ \\
\hline
\end{tabular}

\section{Conclusions}

Lesson preparations and lesson plans are all for teaching in the classroom. The teaching link is a unity of teaching and learning, which is an implementation link. In general, the teaching process is designed in this way. For each lesson, we must first arouse students' curiosity, review old knowledge, inform the learning purpose of the class, elicit new knowledge, explain the important and difficult points of new knowledge, clarify the relationship between old knowledge and new knowledge, and promote the new knowledge. Understanding, eliciting students' reactions, providing opportunities for feedback and correction, providing scenarios for the application of skills, and promoting the transfer of knowledge. We need to guide students to think positively, give them a wide range of divergent thinking scenarios, and cultivate their own knowledge to reconstruct and associate other related knowledge, so as to achieve the purpose of inferring from one another. In this way, students can be motivated to consider the problems more thoroughly and the advantages of careful thinking. At the same time, this allows students to think more about different scenarios, get different conclusions, and give different positive evaluations, which promotes students' characteristics of learning, thinking, and asking more.

In this way, we can achieve the purpose of training students to think actively and learn actively; so as to train students to get different conclusions for the same thing, through different scenarios, and achieve the purpose of students dare to try new methods and new ideas. Innovative talents lay the foundation.

All of these teaching links are student-oriented and formulated according to actual conditions. In the teaching process, we must learn to use it flexibly.

\section{Acknowledgements}

This work was supported by Xinjiang Uygur Autonomous Region Innovation Environment (talent, base) Construction Foundation (Xinjiang NSFC Program Foundation 2020D01A132). Research and implementation of horizontal well inversion optimization interpretation method. Jingzhou Science Technology Foundation (2019EC61-06) and Hubei Science and Technology Demonstration Foundation (2019ZYYD016). 2019 Zhaoqing science and technology innovation guidance project (201904030401), Vertical research planning project of cloud computing and big data Professional Committee of Higher Vocational College of Guangdong Institute of higher education in 2019 (GDJSKT1918). Case teaching course construction of interdisciplinary petroleum software development (YAL202002). Comparative analysis and practice of engineering course teaching process between Chinese and Canadian universities (JY2018012)

\section{References}

[1] Long Chengmei. Student oriented "golden course" in chemical engineering foundation [J]. Shandong Chemical Engineering, 2020,49 (09). 169-170.

[2] Cao Yong. Dilemma and Countermeasures of classroom teaching quality evaluation in Higher Vocational Colleges [J]. Journal of higher education, 2020 (02). 175-177.

[3] Chen Li, Yue Jia, Zhang Shunan, Mu Tingting, Liu Fenglin, Zheng Guisen. Exploration on the application of micro lecture in the teaching of nutrition and food hygiene [J]. Education and teaching forum, 2020 (03). 136-137.

[4] V.K. Voronov,L.A. Gerashchenko,"Cognitive Barriers in Training the Students of Higher Education Institutions, Methodology for Their Elucidation and Overcoming",IJMECS, vol.5, no.2, pp.1-11, 2013.DOI: 10.5815/ijmecs.2013.02.01

[5] Yang Hua, Zhang Mengjie, Zhu Yunguo. Student oriented optimization of theoretical teaching Analysis of questionnaire in genetics classroom [J]. Education and teaching forum, 2018 (17). 95-96.

[6] Feng Xianchao. Application of student-oriented "semi inverted classroom" teaching in Higher Education [J]. Education and teaching forum, 2016 (03). 122-123.

[7] Duan Aihua. Exploration of subjective education method in University Teaching [J]. Journal of Chifeng University (NATURAL SCIENCE EDITION), 2015, 31 (15). 239-240.

[8] S. Justus,Mohammed Sirajudin,"Evaluating the Project based Organizational Teaching-Learning Process", IJMECS, vol.5, no.5, pp.38-48, 2013.DOI: 10.5815/ijmecs.2013.05.05

[9] Li Xiangdong, Xia Bing, Zheng Qiusheng. Cultivation mechanism of graduate students' innovative ability based on subject competition[J]. Computer Education, 2020(10):117-120.

[10] Li Zhixuan. Research on the fusion mechanism of college students' ideological and political education and entrepreneurial talent cultivation $[\mathrm{J}]$. Reference for middle school political teaching, 2020(29): 100. 
[11] Zhang Lingdi, Peng Wei. Analysis of Optimizing University Student Model Selection and Cultivation Mechanism in the New Era[J]. Contemporary Educational Practice and Teaching Research, 2020(14): 28-29.

[12] Mou Jie,Guo Dong,Bai Yunna,Zhang Ying,Yin Xiaoxing.Exploration on the long-term training mechanism of innovative and entrepreneurial talents for college students[J].Pharmaceutical Education,2020,36(02):1-4.

[13] Zheng Lei,Wang Ziqi,Jing Yanqi.Innovative research on the training mechanism of college student party members in the new era[J].Journal of Lanzhou Institute of Education,2020,36(02):52-54.

[14] Hu Tianli,Mu Ye,Sun Yu,Hou Lixin,Gong He.Exploration and Practice of Undergraduates' Innovative Ability Training Model Oriented to Increase Participation[J].Education Teaching Forum,2020(02):204-205.

[15] Li Weiwei,Yang Huashan,Du Yundan,Zhao Zhenhua,Che Yujun,Chen Rongfei.Exploration on Cultivating Learning Drive of College Students[J].Reform and Opening,2019(20):96-98.

[16] Wang Chao,Zhu Weiyi,Zhu Teng.Research on the Countermeasures of Cultivating College Students' Innovation and Entrepreneurship Ability under the Background of "Double First Class" Construction[J].Theoretical Research and Practice of Innovation and Entrepreneurship,2019,2(15):104-105.

[17] Wang Wei, Ishi Yefei, Jiang Li. Long-term training mechanism for innovation and entrepreneurship ability of design college students based on school-enterprise cooperation[J]. Science and Technology Wind, 2018(33):233.

\section{Authors' Profiles}

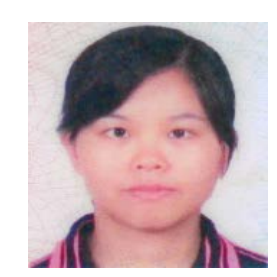

Qiongqin Jiang was born in Hubei, P.R. China, in 1980. Now, she works in school of Computer Science, Yangtze University. His research interest include software engineering, petroleum software technology and big data analysis.

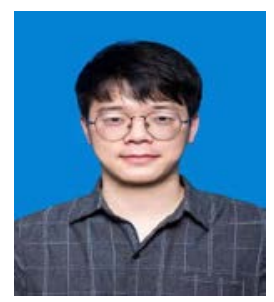

Tian Jin was born in Yichang, Hubei,P.R. China, in 1995.Now he is studying in the school of Computer Science, Yangtze University. His research interest include Graphics processing Image Identification.

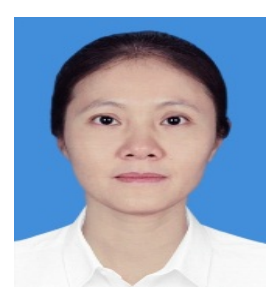

Haiyu Chen was born in LuoDing, Guangdong, P.R. China, in 1978. Now, she works in Zhaoqing Medical College. Her research interest includes Computer application technology, Software Engineering, Database design and big data

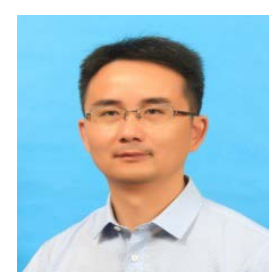

Wenguang Song was born in Wuhan,Hubei,P.R. China, in 1979. Now, he works in school of Computer Science, Yangtze University. His research interest includes software engineering, petroleum software technology and big data analysis. Visiting scholar of Regina University, Canada. E-mail: wenguang_song@yangtzeu.edu.cn

How to cite this paper: Qiongqin Jiang, Tian Jin, Haiyu Chen, Wenguang Song, " Research on Cultivating Undergraduates in the Computer Science Based on Students ", International Journal of Engineering and Manufacturing (IJEM), Vol.10, No.6, pp.32-39, 2020. DOI: $10.5815 /$ ijem.2020.06.04 